\title{
Professional ethics in pharmacy practice: developing a psychometric measure of moral reasoning
}

\author{
Betty B. Chaar · Joanne Brien · Ines Krass
}

Published online: 13 August 2009

(C) Springer Science+Business Media B.V. 2009

Erratum to: Pharm World Sci (2009) 31:439-449

DOI 10.1007/s11096-009-9292-1

We regret that there is an error in the list of authors for this publication.

The correct authorship of this article belongs to the following three authors (not one individual author): Betty B. Chaar*, Joanne Brien* and Ines Krass* (*Faculty of
Pharmacy, University of Sydney). The author for correspondence remains B. B. Chaar (email: b.chaar@pharm. usyd.edu.au).

The online version of the original article can be found under doi:10.1007/s11096-009-9292-1.

B. B. Chaar $(\bowtie) \cdot$ J. Brien · I. Krass

Faculty of Pharmacy, University of Sydney,

Room N508-Bldg A15, Camperdown, NSW 2006, Australia

e-mail: b.chaar@pharm.usyd.edu.au 